\title{
INVESTIGATION OF PHOTONEUTRON CONTAMINATION FROM THE 18-MV PHOTON BEAM IN A MEDICAL LINEAR ACCELERATOR
}

\author{
RAZISKAVA FOTONEVTRONSKIH POŠKODB ZARADI \\ OBSEVANJA Z 18 MV CURKOM FOTONSKIH ŽARKOV V \\ MEDICINSKEM LINEARNEM POSPEŠEVALNIKU
}

\author{
Onur Karaman ${ }^{1 *}$, Ayșe Güneş Tanır², Ceren Karaman ${ }^{3}$ \\ ${ }^{1}$ Medical Imaging Program, Vocational School of Health Services, Akdeniz University, 07070 Antalya, Turkey \\ ${ }^{2}$ Department of Physics, Faculty of Sciences, Gazi University, 06500 Ankara, Turkey \\ ${ }^{3}$ Department of Chemical Engineering, Faculty of Engineering, Pamukkale University, Denzili 20070, Turkey \\ Prejem rokopisa - received: 2019-01-10; sprejem za objavo - accepted for publication: 2019-04-11
}

doi:10.17222/mit.2019.011

In medical applications, high-energy linear accelerators are increasingly used. However, during a cancer treatment, unwanted photoneutrons caused by high-energy photon beams ( $>10 \mathrm{MV})$ increase the secondary cancer risk. This study aimed to investigate the effects of the square field size and distance to the isocenter on the neutron contamination emitted by an Elekta Versa HD medical linear accelerator using a Thermo Scientific RadEye neutron detector. The measurements were carried out for 18-MV photons with different square field sizes and different distances from the isocenter. It was clearly seen that the neutron dose equivalent decreases with both the increasing distance from the isocenter and square field size. Also, in order to analyze the neutron dose equivalent variation with field sizes and distances, Monte Carlo code Fluka was used. It was shown that MC-Fluka modeling and experimental results were consistent with each other. It was concluded that it is crucial to take into consideration the unwanted neutron dose in the radiation treatment.

Keywords: neutron contamination, linear accelerator (LINAC), Monte Carlo simulation, Fluka

$\mathrm{V}$ medicini se vse bolj uporabljajo visoko-energijski linearni pospeševalniki. Vendar pa med obsevanjem bolnikov z rakom prihaja do neželenih sekundarnih učinkov zaradi delovanja fotonevtronov, ki jih seva visoko-energijski fotonski curek $(>10$ MV). Avtorji raziskovali vpliv velikosti in razdalje kvadratnega polja $\mathrm{z}$ enakim središčem na poškodbe povzročene $\mathrm{z}$ nevtroni, ki jih emitira Elekta Versa HD medicinski linearni pospeševalnik. Le-te so zaznavali z nevtronskim detektorjem Thermo Scientific RadEye. Meritve so izvajali pri različnih velikostih in razdaljah od središča polja obsevanja, povzročenega z 18 MV fotoni. Popolnoma nedvoumno so ugotovili, da se jakost nevtronske doze zmanjšuje ekvivalentno s povečevanjem razdalje od središča obsevanja, kot tudi velikosti kvadratnega polja. Prav tako so avtorji, da bi analizirali variiranje doze nevtronov z velikostjo in razdaljo, uporabili računalniško kodo Fluka, ki temelji na metodi Monte Carlo simulacije. Pokazali so, da se simulacije, izdelane z MC-Fluka kodo, dobro ujemajo z eksperimentalnimi rezultati. Avtorji v zaključku poudarjajo, da je za uspešno obsevanje ključno upoštevanje neželene nevtronske doze.

Ključne besede: nevtronske poškodbe, linearni pospeševalnik (LINAC), Monte Carlo simulacija, Fluka

\section{INTRODUCTION}

In order to treat cancer or deep body tumors in patients, in recent years, the medical linac has attracted tremendous attention as a promising high-energy photon-beam source. Despite the fact that when compared with low-energy accelerators, high-energy accelerators exhibit some advantages (i.e., a lower skin dose, a larger depth dose and a lower scattered-radiation dose outside the field), the production of unwanted neutrons is the key issue in the use of high-energy accelerators. ${ }^{1-3}$ The unwanted neutrons are produced due to the interaction of high-energy photons with high-Z metals, especially $\mathrm{W}$ and $\mathrm{Pb}$ used in the head of an accelerator. The threshold-energy values of a photoneutron production for $\mathrm{Pb}$ and $\mathrm{W}$ are $6.19 \mathrm{MeV}$ and $6.17 \mathrm{MeV}$,

*Corresponding author's e-mail:

onurkaraman@akdeniz.edu.tr respectively, while the respective values for $\mathrm{Fe}$ and $\mathrm{Cu}$ are $7.65 \mathrm{MeV}$ and $9.91 \mathrm{MeV}^{4-8}$ The probability of photonuclear reactions increases with the photon energy. Due to the fact that its maximum value in the radiotherapy was found to be $13-18 \mathrm{MeV}$, it can easily interact with a linac head including $\mathrm{Pb}, \mathrm{W}, \mathrm{Fe}$ and $\mathrm{Cu}$. The target and all the collimators are the main parts of a linac head contributing to the photonuclear reaction. Most of the studies reported that these unwanted neutrons emitted from the linac head are not negligible. ${ }^{3,9-11}$ They can cause secondary harmful malignancies as well as contributing an additional dose to the total neutron dose. ${ }^{12,13}$ Neutrons with a radiation weighting factor of 20 also affect the shielding requirements in radiotherapy. So, the neutron contamination should be controlled and minimized. ${ }^{3,14-17}$ Most of the studies were carried out to determine the effects of different parameters such as the field size and the distance from isocenter on the photoneutron production of different medical linear accelerators. How- 
ever, dosimetric measurements are not sufficient to explain the contribution of the photoneutron dose. The majority of studies involve the Monte Carlo (MC) simulations of the linacs. In several studies, different MC codes are applied to show the contribution of the parts of a linac to the neutron contamination and also the effects of the linac model, field size and distance from isocenter. ${ }^{13,18,19}$ In one of these studies, Meshabi et al. simulated an 18-MV photon-beam Elekta SL75/25 accelerator for open and wedged beams and its variation with the field size by means of the MCNPX MC code. It was shown that for open beams, the neutron dose equivalent (NDE) decreased with the increasing field size. In contrast, for wedged beams, it increased with the field size. ${ }^{3} \mathrm{M}$. Jahangiri et al. ${ }^{20}$ investigated the effect of the field size on the neutron dose equivalent in the center and away from it. The results revealed that the NDEs increased with the increasing field sizes, especially for the $5 \mathrm{~cm} \times 5 \mathrm{~cm}$ field size. ${ }^{20}$

The undesirable neutrons originating from different parts of a high-energy linear accelerator have different energies. As a result, it is proper to suppose that if the neutrons produced by different parts of the linac head reach the measuring area in the patient plane, there will be a neutron energy shift. ${ }^{12,21-23}$ In order to model Varian Clinac 2100C with a 18-MV photon beam, J. Ma et al. ${ }^{23}$ used Monte Carlo code MCNPX. They investigated the neutron contamination and determined the numbers of photoneutrons at different field sizes. The authors noted that most of the photoneutrons were produced by the primary collimator (55-60\%) and jaws (15-30\%). J. Pena et al. ${ }^{19}$ figured out the contributions of different components of an 18-MeV Primus linac for the $10 \mathrm{~cm} \times 10 \mathrm{~cm}$ field size. It was reported that the contribution of the primary collimator was $52 \%$ and the contribution of the secondary collimator was $21 \% .{ }^{19}$ In the same manner, J. Becker et al. ${ }^{6}$ reported similar results, consistent with the previous study by J. Pena et al. ${ }^{19}$

It is important to determine which parameter affects the neutron dose equivalent to better evaluate the increase in the total dose given to a patient. The inconsistency of the obtained results in MC modelling can be explained with the differences between the MC codes used for the simulation. According to the authors' knowledge, the simulation of the 18-MV photon beams for an Elekta Versa HD linac made by Fluka has not yet been studied comprehensively. Thus, this study aimed to simulate the head of an Elekta Versa HD linac using the Fluka MC code. Since the Fluka code can process proper electron-nucleus, electron-electron bremsstrahlung and photonuclear interactions over the whole energy range, it is one of the best choices for a simulation ${ }^{24}$. In order to estimate the neutron dose equivalent for different points as well as different field sizes, a Thermo Scientific RadEye neutron detector was used. It is difficult to perform experimental measurements of this kind of doses from neutrons with the standard nuclear instru- mentation. Therefore, a simulation code is useful for simulating the photoneutron production and transportation across the accelerator head. With the help of these simulation tools, the neutron contamination can be evaluated. Monte Carlo code Fluka was used to achieve the goal of this study. Using the Fluka code, it was shown if the experimental measurements were in agreement with the simulation or not.

\section{EXPERIMENTAL PART}

In this work, an Elekta Versa HD medical linac was used to determine the neutron contamination. It is able to generate 6-MV and 18-MV photon beams and electron beams with different energies (i.e., 6-18 MeV) in accordance with the desired treatment. In line with International Atomic Energy Agency (IAEA) TRS-398, the reference dose calibration protocol, the outputs of the linac were calibrated as $1 \mathrm{cGy}=1$ monitor unit (MU). The gantry and collimator angle were positioned at $0^{\circ}$ and vertically oriented, the isocenter was at position $(0,0,0)$ and the linac was operated in the 18 -MV photon mode. A water-equivalent solid slab phantom (PTW RW3) was positioned at the isocenter. Figure 1 introduces the layout of the radiotherapy treatment room. The isocenter is located in the middle of the treatment room.

Dosimetric measurements for the neutron contamination were read by a Thermo Scientific RadEye NL neutron detector, a ${ }^{3} \mathrm{He}$ gas detector. It was calibrated by Thermo Scientific Inc. using ${ }^{252} \mathrm{Cf}$ sources. Since neutrons are neutral particles, their behavior is different from that of charged particles or gamma rays. Therefore, their detection takes place by means of secondary ionized particles/rays produced in their interaction with matter. The incoming neutrons are captured by the trans-

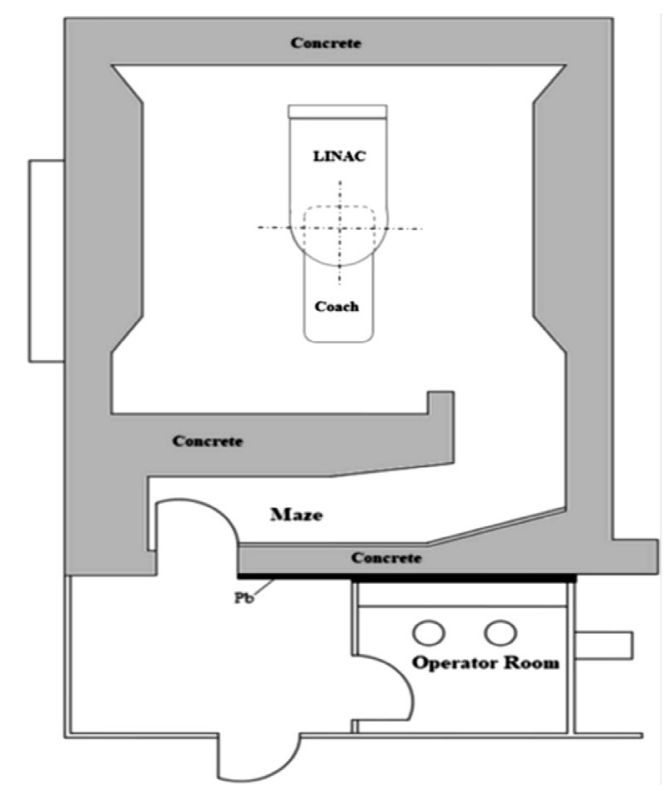

Figure 1: Layout of the radiotherapy treatment room 
ducer material and converted into ionic particles that can be detected by nuclear reactions.

The protons and ${ }^{3} \mathrm{H}$ particles are detected and measured using a typical gas-flow proportional counter filled with the ${ }^{3} \mathrm{He}$ gas. As a result of capturing neutrons by ${ }^{3} \mathrm{He}$, the kinetic energy of $765 \mathrm{keV}$ occurs. This energy is separated as $0.191 \mathrm{MeV}$ for tritium particles and $0.574 \mathrm{MeV}$ for protons. By means of measuring the energy of the products produced in the following reaction, detecting of thermal neutrons is performed.

Thermal-neutron (n) tagging in gaseous proportional counters is achieved with the following reaction:

$\mathrm{n}+{ }^{3} \mathrm{He} \rightarrow \mathrm{p}(573 \mathrm{keV})+{ }^{3} \mathrm{H}(191 \mathrm{keV}) ; \mathrm{Q}=764 \mathrm{keV}(1)$

where $\mathrm{p}$ and ${ }^{3} \mathrm{H}$ ionize the gas molecules and create a track of ion-electron pairs, whose number is proportional to the energy deposited in it. During the detection of thermal neutrons, ${ }^{3} \mathrm{He}$ acts as the stopping medium for them with reaction (1); meanwhile, with a higher stopping power than that of ${ }^{3} \mathrm{He}$, tritium and protons are stopped by the filling gas. ${ }^{25,26}$ The dosimetric measurements taken by the Thermo Scientific RadEye NL neutron detector were analyzed by an automatic reader. To eliminate device-based errors, each measurement was repeated three times.

The effect of the field size on the neutron contamination was analyzed at a source-to-surface distance $(\mathrm{SSD})$ of $100 \mathrm{~cm}$ for the field sizes of $(5 \times 5),(10 \times 10)$, $(20 \times 20),(30 \times 30)$ and $(40 \times 40) \mathrm{cm}^{2}$. In order to analyze the effect of the distance from the isocenter on the neutron contamination, the RadEye NL detector was located at the isocenter and various distances of 10-50 $\mathrm{cm}$ from the central axis (Figure 2).

In the next step of the study, Monte Carlo code Fluka, version 2011.2c.6, was used to simulate the photoneutron production in the Elekta Versa HD linac. MC methods were extensively used to evaluate the characteristics of the neutron contamination.

Figure 3 illustrates the geometry of an accelerator head simulated by the MC Fluka code. The primary electron beam hitting the tungsten target was simulated as a mono-energetic electron beam with an energy of 18

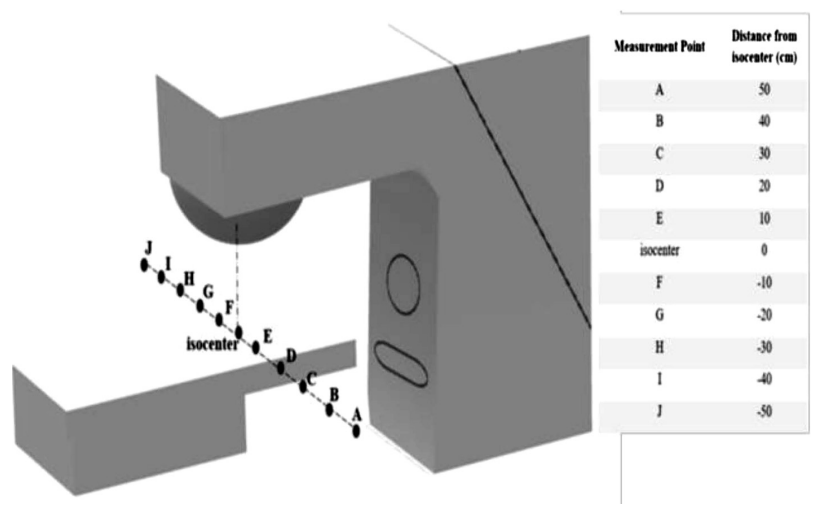

Figure 2: Schematic presentation of the locations of detectors for the measurements around the Electa Versa HD linac

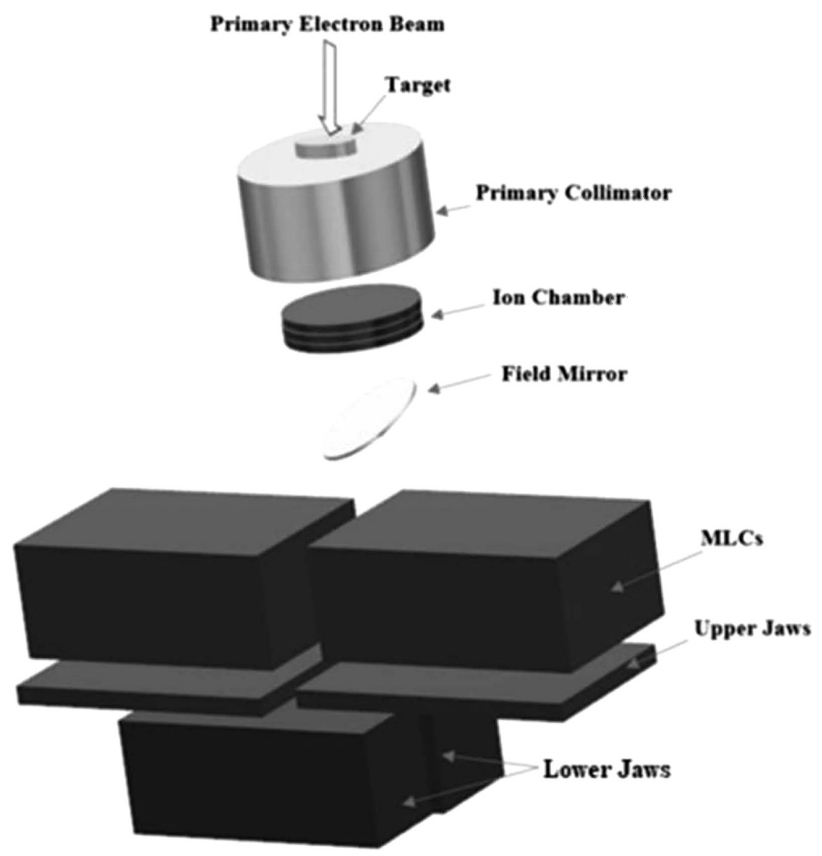

Figure 3: Geometry of the Electa Versa HD linac head simulated by the Fluka code

MeV. Induced X-rays pass through the primary collimator. In order to activate the photoneutron reaction, the simulation parameter in Fluka called the Photonuc card was turned on. At the SSD of $100 \mathrm{~cm},(30 \times 30 \times$ 30) $\mathrm{cm}$, in order to calculate the NDEs, the water-equivalent solid slab phantom was divided into voxels and simulated. To investigate the effect of the field size on the neutron contamination, the jaws and the multi-leaf collimators (MLCs) were set for different field sizes. Each simulation was run on a personal computer (Intel 6 Core, 3.6 GHz CPU, 32 GB RAM). To reduce the statistical uncertainty of each set-up to an acceptable level, the number of histories was set to $2 \times 10^{9}$ primary electrons. During the final step of the study, the simulation was evaluated by comparing the data obtained with dosimetric measurements and MC simulations.

\section{RESULTS}

The photoneutron measurements were done with both dosimetric measurements performed by the Thermo Scientific RadEye NL dosimeter and the MC code Fluka simulation. To evaluate the influence of the distance from the central axis, a statistical analysis was performed separately for each field size. The measurement results were normalized for a 1-Gy photon dose. The measured and MC-simulated NDEs at the patient plane and at different distances from the isocenter are represented in Figure 4. It is clear that the MC-Fluka model of the accelerator complies well with the measured NDEs. It is concluded that the simulation data can be used to analyze the neutron contamination in further studies. 

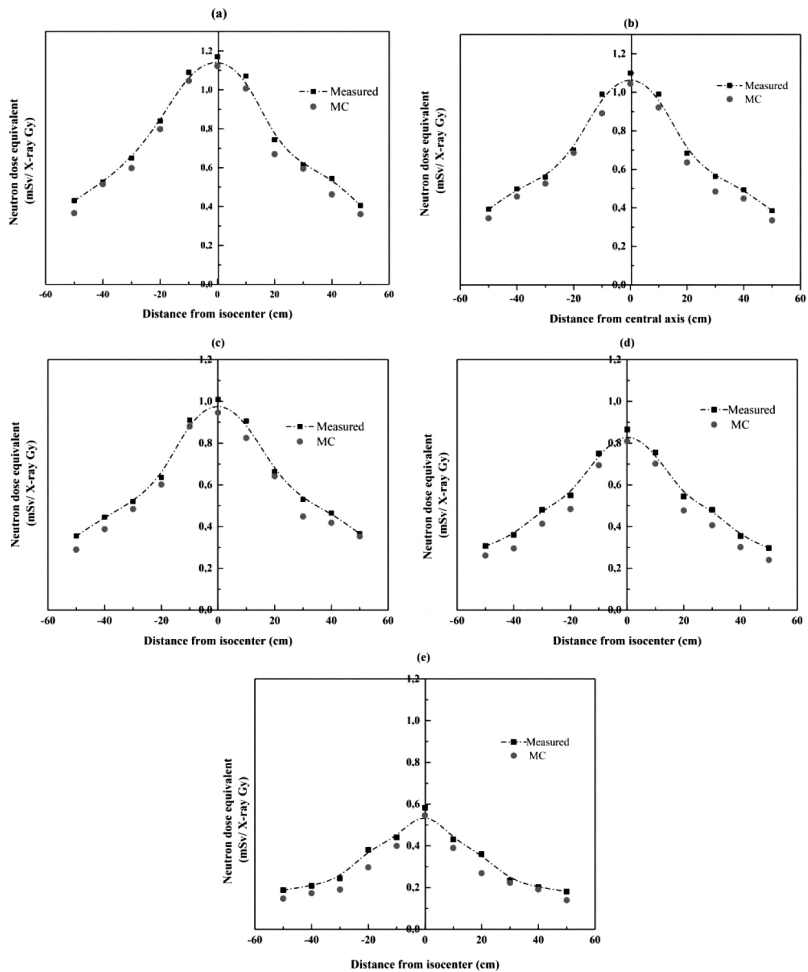

Figure 4: Comparison between experimental measurements and simulations with the MC-Fluka code for different field sizes: a) $5 \mathrm{~cm}$ $\times 5 \mathrm{~cm}$, b) $10 \mathrm{~cm} \times 10 \mathrm{~cm}$, c) $20 \mathrm{~cm} \times 20 \mathrm{~cm}$, d) $30 \mathrm{~cm} \times 30 \mathrm{~cm}$, e) 40 $\mathrm{cm} \times 40 \mathrm{~cm}$

The NDEs measured and MC-simulated at the isocenter for different sizes are presented in Table 1. The results show that there is acceptable agreement between the measured and MC-simulated NDE values for all the sizes considered. The best agreement is achieved for the $5 \mathrm{~cm} \times 5 \mathrm{~cm}$ and $10 \mathrm{~cm} \times 10 \mathrm{~cm}$ field sizes where the average local dose differences are 4.0-5.0\%.

Table 1: Measured and MC-simulated NDEs for different field sizes at the isocenter

\begin{tabular}{|c|c|c|c|}
\hline $\begin{array}{c}\text { Field size } \\
\left(\mathrm{cm}^{2}\right)\end{array}$ & $\begin{array}{c}\text { Measured } \\
\text { NDEs } \\
\left(\mathrm{mSv} \mathrm{Gy}^{-1}\right)\end{array}$ & $\begin{array}{c}\text { MC-simulated } \\
\text { NDEs } \\
\left(\mathrm{mSv} \mathrm{Gy}^{-1}\right)\end{array}$ & $\begin{array}{c}\text { Difference } \\
\%\end{array}$ \\
\hline $5 \times 5$ & 1.17 & 1.13 & 4.0 \\
\hline $10 \times 10$ & 1.10 & 1.05 & 5.0 \\
\hline $20 \times 20$ & 1.01 & 0.95 & 6.3 \\
\hline $30 \times 30$ & 0.87 & 0.83 & 6.5 \\
\hline $40 \times 40$ & 0.58 & 0.55 & 6.2 \\
\hline
\end{tabular}

The dependence of the MC-simulated NDEs on the off-axis is shown in Figure 5. Attention is drawn to the fact that the maximum dose equivalents are observed at the isocenter. By changing the field size from $(5 \times 5) \mathrm{cm}$ to $(40 \times 40) \mathrm{cm}$, the NDEs decrease from $1.13 \mathrm{mSv} \mathrm{Gy}^{-1}$ to $0.55 \mathrm{mSv} \mathrm{Gy}^{-1} \mathrm{X}$-ray at the isocenter. It can be clearly seen in Figure 5 that the NDE decrease with the increasing simulation point takes place far from the isocenter and at a constant field size. This is consistent with the measured NDEs (Figure 4). The results also

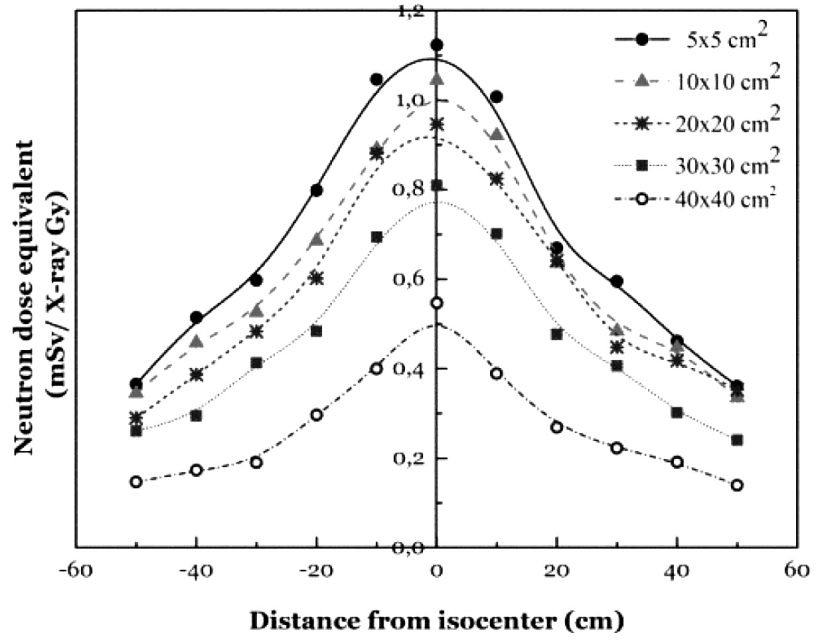

Figure 5: MC-simulated neutron-dose-equivalent variation with the distance from the isocenter for different field sizes

indicate that the MC-simulated NDE values at the isocenter and at $50 \mathrm{~cm}$ are significantly different.

MC-simulated NDEs are given in Figure 6 to show the effect of the field size on the photoneutron contamination. The neutron dose differentiation remains constant for smaller field sizes and starts to decrease for the field sizes larger than $20 \mathrm{~cm} \times 20 \mathrm{~cm}$. Figure 6 clearly shows that the NDEs decrease with the field size. Since the attenuation effect of the secondary collimator jaws decreases with the increasing field size, the variation in the NDEs with the field size is considerable.

According to the NCRP, for 18-MV linac neutrons, measurements can be done between distances of $0.8 \mathrm{mSv} \mathrm{Gy}^{-1}$ and $2.5 \mathrm{mSv} \mathrm{Gy}^{-1}$ from the isocenter and at $50 \mathrm{~cm} .{ }^{27}$ When comparing the results obtained at $50 \mathrm{~cm}$ in this study, we find lower NDEs between $0.41 \mathrm{mSv} \mathrm{Gy}^{-1}$ and $0.18 \mathrm{mSv} \mathrm{Gy}^{-1}$.

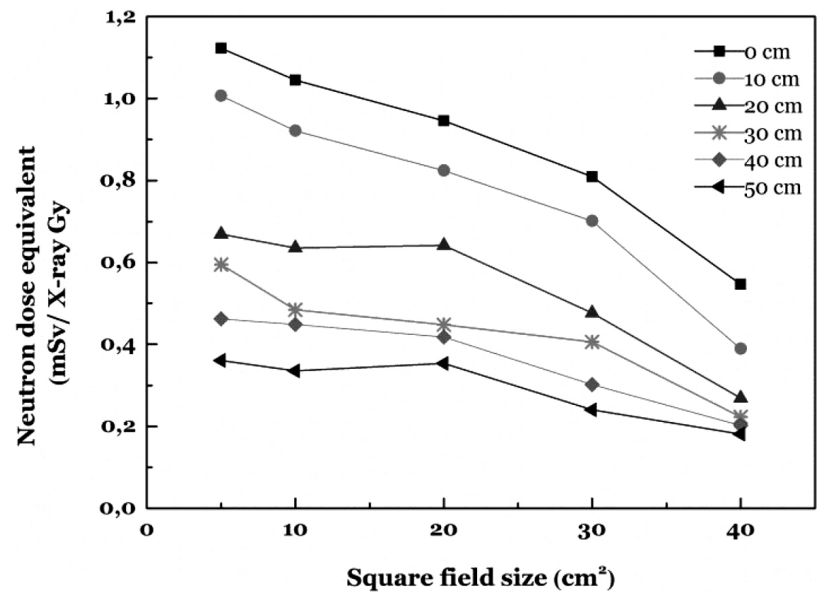

Figure 6: $\mathrm{MC}$-simulated neutron-dose-equivalent variation with the field size for different distances from the isocenter 


\section{DISCUSSION}

The measured and MC-simulated NDEs for varying field sizes at different points from the isocenter are presented in this paper. There are many studies about the effect of the field size on the neutron contamination of high-energy linear accelerators. While some of them agree with each other, others show controversial results. The results of this study show that the photoneutron dose equivalents are maximum at the center of the field and they decrease with the increasing distance from the isocenter. Also, it is proved that with the increasing field size, the NDEs decrease at all points. Using the Monte Carlo Fluka code, the neutron spectrum of the 18-MV photon beam is investigated. The NDEs are found between $1.12 \mathrm{mSv} \mathrm{Gy}^{-1}$ and $0.55 \mathrm{mSv} \mathrm{Gy}^{-1}$ at the isocenter of the field.

The results obtained with experimental measurements partially disagree with the study by M. Jahangiri et al., ${ }^{20}$ in which neutron dosimetry was carried out with CR-39 films using the chemical etching technique. In the study by A. Meshabi et al., ${ }^{18}$ it was demonstrated that a linac with a flattening filter had more neutron fluence than a flattening filter free linac with the same set-up and collimator aperture. ${ }^{18}$ In another study, a Varian 2300C linac was simulated with the Monte Carlo code and it was noted that the NDEs increased with the field size. It was recorded that the secondary collimator was the main neutron-contamination source. ${ }^{28}$

The results of this study are in agreement with the experimental and MC-simulation study by Mesbahi et al. (2010). The authors aimed to investigate the effect of an open beam and wedged beam beside the effect of field size. While for the open beams, the NDEs decreased with increasing field sizes, for the wedged beams, increasing field sizes caused an increase in the NDEs. Closing the jaws caused more neutron attenuation, so the number of photoneutron interactions in the secondary collimator jaws caused an increase in the neutron yield. ${ }^{3}$ Comparing their results with the current results, it can be seen that in this work, the measured and MC-simulated NDEs are too close to each other for open beams. Another Monte Carlo calculation based on the MCNP code version 5 was used to study several components of a 15-MV linac and the NDEs were measured with optically stimulated luminescence (OSL). ${ }^{29}$ They reported that for different field sizes, the NDEs increased due to the closing of the MCL.

In the current study, the comparison between the measured and MC-simulated NDEs is performed at various field sizes opened by the MLC while the collimator jaws are fixed. The NDEs increase due to the closing of the MLC. When the MLCs are closed, more neutrons can be produced in the MLCs made of tungsten. The MC-simulated and measured NDEs are in agreement in every position. However, the NDEs MC-simulated by Fluka are slightly lower than the values measured with the Thermo Scientific RadEye neutron detector, but still within acceptable agreement. Furthermore, the measured NDE values are lower than the NDEs reported by Hashemi et al. (2007). In their study, polycarbonate films were used as neutron detectors, but they were not sensitive to the neutrons produced in the treatment-room walls $^{2}$. There are several important areas such as the floor, wall and ceiling of the treatment room, from which neutrons can scatter.

In this study, during the simulation, the effect of walls on the neutron contamination is also ignored. However, the results are still in contrast to the study by Hashemi et al. (2007). It can be said that these differences may be due to large dosimetric uncertainties associated with the dosimeters. In the study of an MCNPX simulation of a Varian linac by Chibani et al. (2003), the NDE is reported to be $13.3 \mathrm{mSv} / \mathrm{Gy}$ for the $(10 \times 10) \mathrm{cm}$ field. ${ }^{30}$ This is 10 times higher than the NDEs MC-simulated in this work. The reason can be explained with the fact that Electa Versa used in this work is a flattening filter free (FFF) model. The flattening filter is the major source of the head scatter. The studies about the effect of the flattening filter on the neutron contamination verify that by using the FFF mode, the neutron contamination can be reduced.

According to the obtained results, it is clearly seen that the Fluka code can be used to determine the photoneutron contamination inside a radiotheraphy treatment room. As a result, it helps to predict the unwanted neutron dose and provides crucial information about the radiation-protection policy for the staff working at clinics as well as patients.

\section{CONCLUSIONS}

The neutron contamination generated by a high-energy medical linac primarily depends on the treatmentfield size and off-axis distance. This work was mainly motivated by the need to validate and develop accurate computational tools to detect the unwanted neutron dose in radiotherapy rooms. The effects of dosimetric properties of an 18-MV Elekta Versa HD linac on the neutron contamination were determined using both a Thermo Scientific RadEye neutron detector and the Monte Carlo Fluka code simulation. This work proved that the NDEs were a function of the field size, and they increased with the field size. It was also shown that the NDEs recorded at different distances from the isocenter were reduced with the increasing off-axis distance. When comparing the results obtained with dosimetric measurement and simulation, it is concluded that the Monte Carlo Fluka code is a reliable tool for determining the neutron contamination, which can cause a secondary cancer risk in the treatment room. Unwanted neutron doses should not be neglected in a typical radiationtherapy room. Consequently, it is necessary to take them into account. Furthermore, it may also be necessary to 
establish more conservative procedures and guidelines to protect both the staff and the patients.

\section{REFERENCES}

${ }^{1}$ P. J. Rudd, D. Prior, S. Austin-Smith, Neutron contamination of 10 MV X-rays: its relevance to treatment room door and maze design, Br J Radiol, 80 (2007) 954, 469-475, doi:10.1259/bjr/17350806

${ }^{2}$ S. M. Hashemi, B. Hashemi-Malayeri, G. Raisali, P. Shokrani, A. Sharafi, A study of the photoneutron dose equivalent resulting from a Saturne 20 medical linac using Monte Carlo method, Nukleonika, 52 (2007) 1, 39-43

${ }^{3}$ A. Mesbahi, H. Ghiasi, S. R. Mahdavi, Photoneutron and capture gamma dose equivalent for different room and maze layouts in radiation therapy, Radiat Prot Dosimetry, 14 (2010) 3, 242-249, doi:10.1093/rpd/ncp303

${ }^{4}$ M. Zabihzadeh, M. R. Ay, M. Allahverdi, A. Mesbahi, S. R. Mahdavi, M. Shahriari, Monte Carlo estimation of photoneutrons contamination from high-energy X-ray medical accelerators in treatment room and maze: a simplified model, Radiat Prot Dosimetry, 135 (2009) 1, 21-32, doi:10.1093/rpd/ncp097

${ }^{5}$ A. Facure, R. C. Falcao, A. X. Silva, V. R. Crispim, J. C. Vitorelli, A study of neutron spectra from medical linear accelerators. Appl Radiat Isotopes, 62 (2005) 1, 69-72, doi:10.1016/j.apradiso.2004. 05.072

${ }^{6}$ J. Becker, E. Brunckhorst, R. Schmidt, Photoneutron production of a Siemens Primus linear accelerator studied by Monte Carlo methods and a paired magnesium and boron coated magnesium ionization chamber system, Phys Med Biol, 52 (2007), 6375-6387, doi:10.1088/0031-9155/52/21/002

${ }^{7}$ N. Golnik, M. Zielczynski, W. Bulski, P. Tulik, T. Palko, Measurements of the neutron dose near a $15 \mathrm{MV}$ medical linear accelerator, Radiat Prot Dosimetry, 126 (2007), 619-622, doi:10.1093/rpd/ ncm 125

${ }^{8}$ W. P. Swanson, Calculation of neutron yields released by electrons incident on selected materials, Health Phys, 35 (1978), 353-367, doi:10.1097/00004032-197808000-00019

${ }^{9}$ R. C. McCall, H. E. Hootman, Heavy metal shielding for neutron sources, Health Phys, 35 (1978) 4, 570-571

${ }^{10}$ J. C. Rivera, R. C. Falcao, C. E. Dealmeida, The measurement of photoneutron dose in the vicinity of clinical linear accelerators, Radiat Prot Dosimetry, 130 (2008), 403-409, doi:10.1093/ $\mathrm{rpd} / \mathrm{ncn} 065$

${ }^{11}$ S. F. Kry, U. Titt, D. Followill et al., A Monte Carlo model for out-of-field dose calculation from high-energy photon therapy, Med Phys, 34 (2007), 3489-3499, doi:10.1118/1.2756940

${ }^{12}$ A. Zanini, E. Durisi, F. Fasolo et al., Monte Carlo simulation of the photoneutron field in linac radiotherapy treatments with different collimation systems, Phys Med Bio, 49 (2004) 4, 571-582, doi:10.1088/0031-9155/49/4/008

${ }^{13}$ C. Ongaro, A. Zanini, U. Nastasi, J. Rodenas, G. Ottaviano, C. Manfredotti, Analysis of photoneutron spectra produced in medical accelerators, Phys Med Bio, 46 (2001) 3, 897-897, doi:10.1088/ 0031-9155/45/12/101

${ }^{14}$ L. Donadille, F. Trompier, I. Robbes et al., Radiation protection of workers associated with secondary neutrons produced by medical linear accelerators, Radiat Meas, 43 (2008), 939-943, doi:10.1016/ j.radmeas.2008.01.018

${ }^{15}$ M. Poje, A. Ivkovic, S. Jurkovic et al., The neutron dose equivalent around high energy medical electron linear accelerators, Nucl
Technol Radiat Prot, 29 (2014), 207-212, doi:10.2298/ NTRP1403207P

${ }^{16}$ A. K. Jaradat, P. J. Biggs, Measurement of the leakage radiation from linear accelerators in the backward direction for 4, 6, 10, 15, and 18 MV X-ray energies, Health Phys, 92 (2007), 387-395, doi:10.1016/ j.radmeas.2008.01.018

${ }^{17}$ W. F. Rebello, A. X. Silva, A. Facure, Multileaf shielding design against neutrons produced by medical linear accelerators, Radiat Prot Dosimetry, 128 (2008), 227-233, doi:10.1093/rpd/ncm312

${ }^{18}$ A. Mesbahi, A Monte Carlo study on neutron and electron contamination of an unflattened 18-MV photon beam, App Radiat Isotopes, 67 (2009) 1, 55-60, doi:10.1016/j.apradiso.2008.07.013

${ }^{19}$ J. Pena, L. Franco, F. Gomez, A. Iglesias, J. Pardo, M. Pombar, Monte Carlo study of Siemens PRIMUS photoneutron production, Phys Med Biol, 50 (2005), 5921-5933, doi:10.1088/00319155/50/24/011

${ }^{20}$ M. Jahangiri, P. Hejazi, S. M. Hashemi, A. Haghparast, B. Hajizadeh, The effect of field size and distance from the field center on neutron contamination in medical linear accelerator, Int J Adv Biol Biom Res, 3 (2015) 1, 97-104

${ }^{21}$ C. Chen, R. Sheu, C. Yeh, U. Lin, S. Jiang, A detailed study on the neutron contamination for a $10 \mathrm{MeV}$ medical electron accelerator, Nucl Instrum Methods Phys Res, Sect A: Accel, Spectrom, Detect Assoc Equip, 562 (2006), 1033-1037, doi:10.1016/j.nima.2006. 02.089

${ }^{22}$ R. M. Howell, M. S. Ferenci, N. E. Hertel, G. D. Fullerton, Investigation of secondary neutron dose for 18 MV dynamic MLC IMRT delivery, Med Phys N Y Inst Phys, 32 (2005), 786-793, doi:10.1118/1.1861162

${ }^{23}$ A. Ma, J. Awotwi-Pratt, A. Alghamdi, A. Alfuraih, N. M. Spyrou, Monte Carlo study of photoneutron production in the Varian Clinac 2100C linac, J Radioanal Nucl Chem, 276 (2008) 1, 119-123 doi:10.1007/s10967-007-0419-3

${ }^{24}$ A. Fasso, A. Ferrari, P. R. Sala, Photonuclear reactions in FLUKA: cross sections and interaction models, AIP Conf Proc, 769 (2005), 1303-1306 doi:10.1063/1.1945245

${ }^{25}$ H. Brick, A. Ivkovic, M. Kasabasic et al., The influence of field size and off-axis distance on photoneutron spectra of the 18 MV Siemens Oncor linear accelerator beam, Radiat Meas, 93 (2006), 28-34, doi:10.1016/j.radmeas.2016.07.002

${ }^{26}$ F. D. Amaro, C. M. B. Monteiro, J. M. F. dos Santos, A. Antognini, Novel concept for neutron detection: proportional counter filled with ${ }^{10}$ B nanoparticle aerosol, Nature Scientific Reports, 7 (2017), 41699, doi:10.1038/srep41699

${ }^{27}$ National Council on Radiation Protection and Measurements (NCRP), Neutron contamination from medical accelerators, Washington DC, USA, 1984 (NCRP Report No. 79)

${ }^{28}$ H. M. Garnica-Garza, Characteristics of the photoneutron contamination present in a high-energy radiotherapy treatment room, Phys Med Biol, 50 (2005), 531-539, doi:10.1088/0031-9155/50/3/010

${ }^{29}$ I. Israngkul-Na-Ayuthaya, S. Suriyapee, P. Pengvanich, Evaluation of equivalent dose from neutrons and activation products from a 15-MV X-ray LINAC, J Rad Res, 56 (2015) 6, 919-926, doi:10.1093/ jrr/rrv045

${ }^{30}$ O. Chibani, C. C. Ma, Photonuclear dose calculations for highenergy photon beams from Siemens and Varian linacs, Med Phys, 30 (2003), 1990-2000, doi:10.1118/1.1590436 